\title{
Development of Indel markers for the selection of Satsuma mandarin (Citrus unshiu Marc.) hybrids that can be used for low-cost genotyping with agarose gels
}

\author{
Takahiro Noda $\cdot$ Kaoru Daiou $\cdot$ Takashi Mihara $\cdot$ Yukio Nagano
}

Received: 22 January 2020/ Accepted: 19 June 2020/Published online: 29 June 2020

(C) The Author(s) 2020

\begin{abstract}
Cross-breeding between cultivars of Satsuma mandarins is difficult because of the seeds' polyembryonic characteristics. Even if a seed is obtained by hybridization, the seed contains only one zygotic embryo (hybrid embryo) and many nucellar embryos. Therefore, for efficient cross-breeding, it is necessary to select a zygotic embryo from among the nucellar embryos. To identify the zygotic embryo, we have developed 119 Indel markers that can be clearly detected by simple agarose gel electrophoresis by mining the Indel region from the resequencing analysis of the short reads of Satsuma mandarin against the reference genome of Satsuma mandarin. Additionally, we showed that the genotype determined by these markers can be used as an
\end{abstract}

Electronic supplementary material The online version of this article (https://doi.org/10.1007/s10681-020-02654-2) contains supplementary material, which is available to authorized users.

T. Noda $(\bowtie) \cdot$ K. Daiou

Kumamoto Prefectural Agricultural Research Center, 3801, Sakae, Koshi-shi, Kumamoto 861-1113, Japan e-mail: noda-t-dw@pref.kumamoto.lg.jp

T. Mihara

Kumamoto Prefectural Fruit Tree Research Institute, 2566, Toyofuku Matsubase-machi, Uki-shi,

Kumamoto 869-0524, Japan

Y. Nagano

Analytical Research Center for Experimental Sciences,

Saga University, 1 Honjo-machi, Saga 840-8502, Japan indicator for the selection of zygotic embryo-derived individuals. In addition, many of the developed Indel markers were found to be used for genotyping Satsuma mandarin as well as other citrus species and relatives. This codominant DNA marker that can be detected by low-cost, simple electrophoresis is expected to be used for the identification of zygotic embryo-derived individuals and for various purposes such as cultivar identification.

Keywords Citrus $\cdot$ Polyembryony $\cdot$ Zygotic embryo $\cdot$ Indel marker

\section{Introduction}

The Satsuma mandarin is the most widely cultivated citrus fruit crop in Japan, and it accounted for $62.1 \%$ (41.8 kha) of all citrus acreage (67.3 kha) in 2018 (https://www.e-stat.go.jp/). The main breeding method for Satsuma mandarin involves using naturally occurring mutations such as bud sport, from which cultivars with different fruit traits, such as early and late maturity, have been developed. Although improvement of the fruit traits by hybridizing between cultivars is desired, breeding of hybrids between Satsuma mandarin cultivars has rarely been conducted. Because cross-breeding between Satsuma mandarin cultivars is technically challenging owing to the trait of male flowers being sterile (Yamamoto et al. 1995) 
and its polyembryonic properties, breeding based on somatic mutation has been the main breeding method (Nishiura 1964, 1968; Omura and Shimada 2016).

Regarding male sterility of the Satsuma mandarin, methods to improve pollen fertility by adjusting temperature conditions during pollen development have been reported (Yang and Nakagawa 1969, 1970), and it is considered possible to cross the cultivars by artificial pollination with fertile pollen. However, the Satsuma mandarin is polyembryonic; thus, even if it can be crossed by artificial pollination, the seed contains only one zygotic embryo (hybrid embryo) and many nucellar embryos. The number of embryos of the Satsuma mandarin has been reported to be approximately 10-30 (Kaneyoshi et al. 1997). For efficient cross breeding, it is necessary to select a zygotic embryo from many nucellar embryos.

Several methods for identifying nucellar and zygotic embryos in citrus fruits have been developed and used; these include vegetative morphology characterization (Furr and Reece 1946; Cameron and Soost 1979; Bowman et al. 1995), infrared spectroscopy (Pieringer and Edwards 1967), chromatography (Albach and Redman 1969; Stanley and Jurd 1971; Tatum et al. 1974; Weinbaum et al. 1982), and isozyme pattern analysis (Esen and Soost 1974; Iglesias et al. 1974; Moore and Castle 1988; Ashari et al. 1988; Anderson et al. 1991). Moreover, random amplified polymorphic DNA (RAPD) analysis (Bastianel et al. 1998; Vilarinhos et al. 2000; Mondal and Saha 2014) and inter-simple sequence repeat-polymerase chain reaction (ISSR-PCR) (Shareefa et al. 2009) have been reported as being effective DNA markers in terms of speed and simplicity. However, as these markers are not intended to detect specific loci showing polymorphism, to improve reproducibility, they must be converted to a single marker [e.g., a sequence tagged site (STS)] that detects one locus by designing specific primers. In recent years, simple sequence repeat (SSR) markers have been used successfully to identify zygotic embryos (Ruiz et al. 2002; Carlos de Oliveira et al. 2002; Rao et al. 2008; Shareefa et al. 2009; Jannati et al. 2009; Yildiz et al. 2013; Woo et al. 2019). However, polymorphisms detected in most of the SSR markers were short in DNA size, and this requires either advanced and expensive equipment, such as a capillary DNA sequencer, or not complicated but time-consuming procedures, such as polyacrylamide gel electrophoresis. Compared to these methods, the use of agarose gel electrophoresis is both inexpensive and straightforward. In addition, the cleavage amplified polymorphic sequence (CAPS) markers that can be detected by simple agarose electrophoresis has been reported (Shimada et al. 2014), and can be applied to identifying nucellar and zygotic embryos. However, this method requires a restriction enzyme that is specific for the PCR product of one allele, which complicates the process.

Due to recent advances in DNA sequencing technology, and the successful completion of citrus genome sequencing projects, reference genome sequences of various citrus and related species have become publicly available, including sweet orange (Wu et al. 2018), pummelo (Wang et al. 2017), citron (Wang et al. 2017), mandarin (Wang et al. 2018), clementine (Liu et al. 2018), Ichang papeda (Wang et al. 2017), kumquat (Liu et al. 2018), and Chinese box orange (Wang et al. 2017). Moreover, whole genome resequencing data of approximately 100 cultivars, including the reference genome sequence of Satsuma mandarin, are available (Wu et al. 2018; Wang et al. 2017; Shimizu et al. 2017). Polymorphism information, such as single-nucleotide polymorphisms (SNPs) and insertion/deletion (Indel), can be obtained easily by mapping the resequencing data against the reference genome.

The study had three objectives: first, to develop Indel DNA markers that can distinguish clearly between heterozygous and homozygous genotypes using a simple and inexpensive method, "agarose gel electrophoresis;" second, to identify individuals derived from both zygotic and nucellar embryos using the Indel markers developed in hybrids between Satsuma mandarin cultivars; third, to study the transferability of the Indel markers developed to other citrus cultivars and close relatives.

\section{Materials and methods}

\section{Plant material}

The cultivars of a selection of the Satsuma mandarins used in the cross-breeding experiment were "Imagawa", as the female parent, and "EC11," as the male parent. All plants were grown at the Kumamoto prefectural fruit tree research institute $\left(130^{\circ} 42^{\prime} \mathrm{E}, 32^{\circ}\right.$ $38^{\prime} \mathrm{N}$; altitude of $49 \mathrm{~m}$ ). 
To obtain fertile pollen, the male parent EC11 cultivar planted in pots (height $297 \mathrm{~mm} \times$ diameter $256 \mathrm{~mm}$ ) was grown in a greenhouse with a minimum temperature of $20{ }^{\circ} \mathrm{C}$. To avoid the contamination of other citrus pollen, pollen was prepared from mature buds. Specifically, the buds were opened, and the closed anthers inside were taken out using tweezers. To obtain the mature pollen from the closed anthers, the anthers were placed in a Petri dish lined with filament paper, covered to prevent overdrying, and kept in the dark at $26^{\circ} \mathrm{C}$ overnight to allow the anthers to open naturally. Pollen was then taken from the open anthers, and wrapped in a paraffin paper, and stored at $-30{ }^{\circ} \mathrm{C}$ until use.

Artificial cross experiments were performed in 2018 and 2019 when the plants were in full bloom (early May). Mature and uniform flowers were selected, pollinated with a cotton swab, and covered with paper bags $(75 \mathrm{~mm} \times 79 \mathrm{~mm})$ coated with paraffin wax.

To confirm the application of the developed Indel markers to various citrus cultivars and their close relatives, four mutation cultivars of Satsuma mandarin ("Aoshima," "Imamura," "Kawata," and "Shirakawa") and other eight citrus hybrid cultivars ["Ariake" ("Tsunonozomi" $\times$ "Murcott"), "Asumi" ("Okitsu 46 gou" $\times$ "Harumi"), "Asuki" ("Okitsu 46 gou" $\times$ "Harumi”), "EC10" (“Ariake" $\times$ "Harumi"), "Harehime" ("E$647 " \times$ "Miyagawa Wase"), "Tsunokagayaki" ("KyOw No. 14" $\times$ "Encore"), "Seinannohikari" ("EnOw No. 21" × "Youkou"), and "Setoka" ("Tsunonozomi" $\times$ "Murcott")] were used as the samples of the genus Citrus. In addition, one species of the genus Fortunella and one species of the genus Poncirus were used. The application numbers of the plant variety protection system in Japan are 26,542 for "Asumi," 32,235 for "Asuki," 24,962 for "EC10," 13,718 for "Harehime," 21,450 for "Tsunokagayaki," and 21,449 for "Seinannohikari." "Ariake" and the four mutant cultivars of the Satsuma mandarin are not numbered. All of the plants used in this study were stock strains from our laboratory.

Embryo rescue culture and acclimation

Immature citrus seeds formed by the artificial hybridization were collected approximately 100 days' after pollination. After sterilizing the surface of the fruit with $70 \%$ ethanol, a $2-\mathrm{cm}$ incision was made at the top and bottom of the fruit using a knife, and the seeds were taken out through the cut surface of the fruit using thrusting tweezers. The seed coat was removed, and multiple embryos were individually separated from the micropylar end of the seed using a needle and separately cultured in vitro on culture medium: Murashige and Skoog (1962) supplemented with $0.1 \mathrm{M}$ maltose, $5 \times 10^{-6} \mathrm{M}$ gibberellin $\mathrm{A} 3$ (GA3), $3.0 \mathrm{~g} / \mathrm{L}$ gelrite (Sigma-Aldrich) at pH 5.6 and autoclaved for $20 \mathrm{~min}$. at $121{ }^{\circ} \mathrm{C}$, then, $4 \mathrm{~mL}$ were poured into glass jars $(18 \mathrm{~mm} \times 120 \mathrm{~mm})$. All cultures were incubated at $25{ }^{\circ} \mathrm{C}$, with a 16 -h photoperiod in our culture rooms with controlled environmental conditions.

Plants obtained from embryo rescue culture were transferred to pots containing the steam-sterilized artificial soil mixture MKK 5gou (Minami Kyushu Chemical Industry, Miyazaki, Japan). Pots were placed in sealed plastic boxes to prevent excessive transpiration and incubated for approximately 14 days in the same culture room under the same embryo culture conditions. The lids of the sealed plastic boxes were then opened gradually over approximately 14 days, and the plants were grown for approximately $7 \mathrm{~d}$ with the lids being opened. Subsequently, the plants were grown in a temperature-controlled greenhouse set at $18-25^{\circ} \mathrm{C}$.

\section{DNA extraction}

Total genomic DNA was purified using the DNA extraction kit 'DNAs-ici!-P' (RIZO Inc., Ibaraki, Japan). The quality of the DNA extracted from each of the samples was examined using $1.5 \%$ agarose gel electrophoresis, and a direct comparison was made between the visibility and size of the extracted DNA and that of a lambda DNA/Hind III or a 100 bp DNA ladder maker. In addition, the quantity of each extracted sample was measured at 260/280 nm absorbance using a Nanodrop 1000 spectrophotometer (Invitrogen, Waltham, Massachusetts, USA).

Mining of Indel sequences from Satsuma mandarin genome information

The reference genome sequence of the Satsuma mandarin was obtained from http://www. citrusgenome.jp/upm.tar.gz. Paired-end reads of the 
Satsuma mandarin were downloaded from the DDBJ Sequence Read Archive (http://trace.ddbj.nig.ac.jp/ dra/index_e.shtml; Accession no. DRA007071). Adapter sequences and low-quality regions were removed from these reads via Trimmomatic (version 0.36) (Bolger et al. 2014). Paired-end reads were mapped to the reference genome of the Satsuma mandarin using bwa (version 0.1.17) ( $\mathrm{Li}$ and Durbin 2009). Samtools (Li et al. 2009) were used to sort the mapping results and remove secondary alignments. GATK-HaplotypeCaller (version 4.0.10.0) (McKenna et al. 2010) was used to create a vcf (variant call format) file (Danecek et al. 2011). The resulting vcf file was analyzed to select candidate Indel regions. Sequences for detecting heterozygous loci for the subsequent analysis were chosen by visual assessment of these candidates using the genome viewer software Integrative Genomics Viewer (IGV) (Thorvaldsdóttir et al. 2013).

For the selection of Indel regions by resequencing analysis, we selected regions comprising unique reads, which were indicated by gray in visualization created using IGV, that map to only one locus in the reference sequence. Loci that appeared to be the highly conserved heterozygous Indel regions in genomes were selected according to specific criteria, including an allele frequency of 0.500 , a mapping quality score (Li et al. 2008) of 50 or more, a minimum read depth of 40 , and a maximum depth of 150 . In addition, the PCR primers were set to amplify the presence of a single Indel but the near absence of SNVs within the 150-300 bp region to be amplified, and they were designed using the data of nine linkage groups (LGs), which was the same as the number of citrus chromosomes (Frost 1925; Nakamura 1929).

\section{Primer design for Indel regions}

The sequences containing selected Indel regions were used for primer design using the Primer3-Plus website (http://www.bioinformatics.nl/cgi-bin/primer3plus/ primer3plus.cgi). The parameters were 150-300 bp amplicon size, $50-60{ }^{\circ} \mathrm{C}$ primer melting temperature (Tm), and 40-60\% primer GC content. To amplify multiple Indel markers simultaneously in a single reaction condition, we designed primers for each Indel marker to have the same PCR amplification conditions.
PCR amplification

PCR amplification mixtures comprised $0.1 \mu \mathrm{L}$ of Blend $\mathrm{Taq}^{\circledR}{ }^{\circledR}$ (Toyobo, Osaka, Japan) (2.5 units $/ \mu \mathrm{L}$ ), $1.0 \mu \mathrm{L}$ of $10 \times$ buffer for Blend Taq ${ }^{\circledR}, 1.0 \mu \mathrm{L} \mathrm{dNTP}(2$ $\mathrm{mM}$ each), $0.2 \mu \mathrm{L}$ of forward and reverse primers (10 $\mu \mathrm{M})$, and $1.0 \mu \mathrm{L}$ of template DNA $(40 \mathrm{ng} / \mu \mathrm{L})$ and were made up to $10 \mu \mathrm{L}$ with sterile $\mathrm{ddH}_{2} \mathrm{O}$. The TP600 PCR thermal cycler (Takara Bio Inc, Shiga, Japan) was used to amplify Indel markers. Online Resource 1 lists the primers used. Then, we performed three-step PCR: denaturation for $5 \mathrm{~min}$ at $95{ }^{\circ} \mathrm{C}, 30$ cycles of $30 \mathrm{~s}$ denaturation at $95^{\circ} \mathrm{C}$, primer annealing for $30 \mathrm{~s}$ at $55^{\circ} \mathrm{C}$ and primer extension at for $30 \mathrm{~s}$ at 72 ${ }^{\circ} \mathrm{C}$. The mixtures were then stored at $4{ }^{\circ} \mathrm{C}$.

To confirm the separation pattern of the amplified PCR fragments, agarose gel electrophoresis was performed using a $4 \%$ gel (Agarose KANTO HC; Kanto Chemical. Tokyo. Japan) visualized by staining with ethidium bromide. Moreover, for precise measurement of the amplified PCR fragments and for validation of the agarose results, a microchip electrophoresis system (MCE-202 MultiNA; Shimadzu. Kyoto. Japan) was used with the DNA-500 reagent kit, which can be used to highly accurately and quickly analyze samples.

\section{$\mathrm{T} 7$ endonuclease assay}

PCR fragments were divided into two groups, and $0.1 \mathrm{U}$ of T7 endonuclease (New England Biolabs) was added to one group and incubated overnight at $24{ }^{\circ} \mathrm{C}$. The undigested and digested samples were analyzed via electrophoresis using the methods described.

Genotyping by Indel markers

The genotypes were expressed as follows: LS (heterozygous), in the case of the presence of a long homoduplex fragment, a short homoduplex fragment, and heteroduplex fragment(s); LL (homozygous), in the case of the presence of a long homoduplex fragment only; SS (homozygous), in the case of the presence of short homoduplex fragment only; and X, in the case of types different from those above. 
Hierarchical cluster analysis

To cluster analysis, genotype of 119 Indel marker profiles were transformed into the matrix data, where the LL is scored as 3, LS as 2, SS as 1, and N.D. as 0 . Because genotype $\mathrm{X}$ was defined as a generic term that includes various band patterns other than LS, LL or SS, it was treated as missing values in the matrix data. Cluster analysis was performed on the basis of a complete link method (Defay 1977) and square Euclidean distance. The analysis was conducted using Ekuseru-Toukei (Social Survey Research Information Co., Ltd. Tokyo. Japan).

\section{Results}

As an example, Fig. 1 shows the region where the Indel marker LG1-4 was created. This region only comprised unique reads, indicated in gray in IGV, with a single Indel in the PCR amplification region and few SNVs. The mapping depth of this region was 54, and the mapping quality was 60.00 . In addition, the allele frequency was 0.500 , showing that the ratio of depth between the deleted loci and its adjacent loci was 1:2, indicating that this region has heterozygous loci. Therefore, the Indel marker LG1-4 is a marker to detect heterozygous regions containing $31 \mathrm{bp}$ of Indel sequence. Similar regions were selected from the whole genome, and PCR primers were designed accordingly.

The selected Indel markers are shown in Online Resource 1. These markers were created from the same nine linkage groups as the number of chromosomes, resulting in a total of 119 markers: 10 from LG1, 12 from LG2, 12 from LG3, 14 from LG4, 16 from LG5, 21 from LG6, 15 from LG7, 11 from LG8, and 8 from LG9. The maximum size of an Indel was 38 bp (LG2-12), and the minimum was 14 bp (LG6-18, LG6-26). The maximum and minimum mapped depths of the selected genomic regions were 107 (LG3-8) and 42 (LG3-2), respectively. For all markers, the allele frequency was 0.500 , and the mapping quality was approximately 60 .

Microchip electrophoresis was used to evaluate the size of the PCR-amplified fragments size. A total of 148 sets of primers were designed for amplification of Indel markers; however, 29 sets were excluded for reasons of no amplification, weak amplification, or the

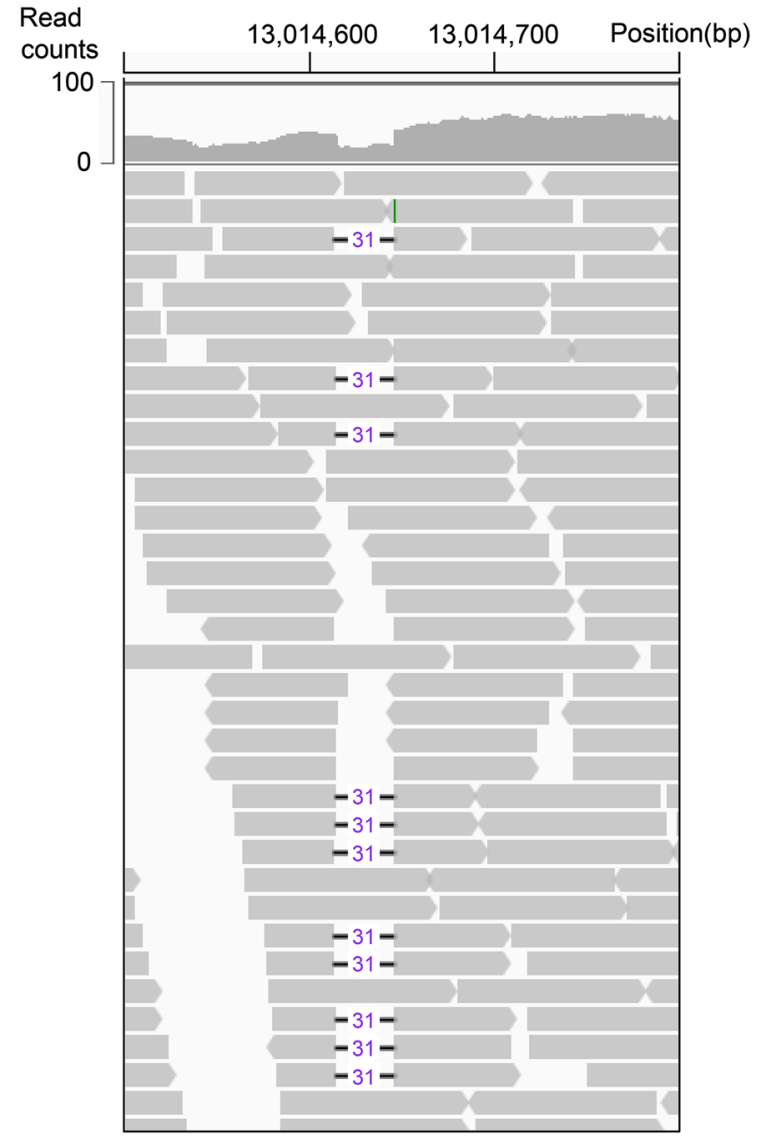

Fig. 1 Visual assessment of the candidate Indel locus by the Integrative Genomics Viewer. The region where the Indel marker LG1-4 was created is shown as an example. For the selection of indel regions, we selected regions comprising unique reads, indicated in gray in IGV, that mapped to only one locus of the reference genome. The mapping depth of this region was 54 and the allele frequency was 0.500 , showing that the ratio of depth between deleted loci and its adjacent loci was 1:2. PCR primers were set to amplify the presence of a single Indel but the near absence of SNVs within the 150-300 bp region to be amplified. The PCR amplification range of the Indel marker LG1-4 is from $13,014,540 \mathrm{bp}$ to $130,014,741 \mathrm{bp}$. Theoretical PCR products' sizes of homoduplexes are $171 \mathrm{bp}$ and $202 \mathrm{bp}$ (Indel size $31 \mathrm{bp}$ )

appearance of an unexpected band. For the 119 selected markers, nearly all the PCR-amplified fragments of Indel markers contained amplified fragments of theoretical size (Online Resource 1). However, one or two slower-mobility fragments were detected in each PCR product as larger fragments than the theoretical length of two fragments. Because the PCR products of heterozygous regions, such as the Indel region, were a mixture of homoduplex and 
heteroduplex DNA, the slower-mobility fragments are considered heteroduplex DNA. To confirm this, PCR products were subjected to $\mathrm{T} 7$ endonuclease treatment, a cleavage enzyme specific for heteroduplex DNA. In all Indel markers tested, T7 endonuclease cleaved only PCR products with slow electrophoretic mobility. As examples, Fig. 2a shows the Indel marker result for each LG (nine Indel markers).

At the same time, by agarose gel electrophoresis the separation pattern was confirmed using the same nine Indel markers. Whereas microchip electrophoresis separated DNA fragments into two fragments of homoduplex DNA and one or two fragments of heteroduplex DNA as described above, agarose gel electrophoresis separated them into three distinct bands (two fragments of homoduplex DNA and one fragment of heteroduplex DNA) in all Indel markers tested (Fig. 2b). In addition, the gel images of all 119 developed Indel markers using agarose gel electrophoresis are shown in Online Resource 2. Among the Indel markers developed, band separation was also possible in LG6-18 and LG6-26, which have the smallest Indel size at $14 \mathrm{bp}$. Most Indel markers were detected as three bands, and as in Fig. 2, the uppermost band was cleaved by the $\mathrm{T} 7$ endonuclease enzyme (data not shown). Thus, many markers were detected as three bands of two homoduplex DNAs with one heteroduplex DNA above them. In addition, several Indel markers, such as LG2-13, were detected as two homoduplex DNAs without a clear separation of heteroduplex DNA. However, the detection of two homoduplex DNA bands of different sizes indicates that the PCR amplification region was heterozygous.

These results indicate that agarose gel electrophoresis can provide sufficient information to determine the zygosity of the PCR amplification region. Thus, we have shown that the Indel marker developed can clearly distinguish between heterozygous and

(a)

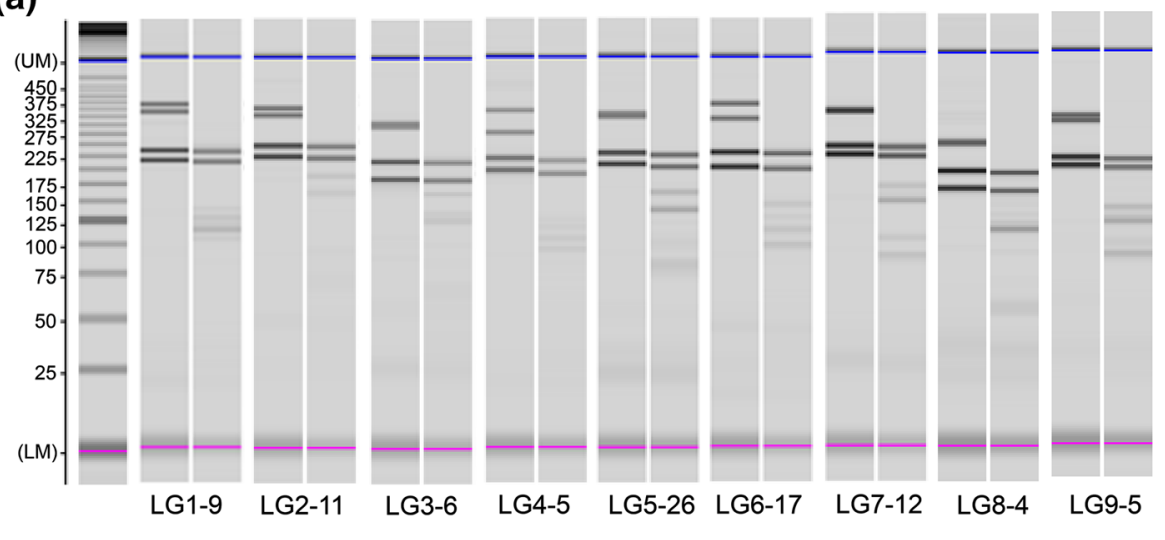

(b)
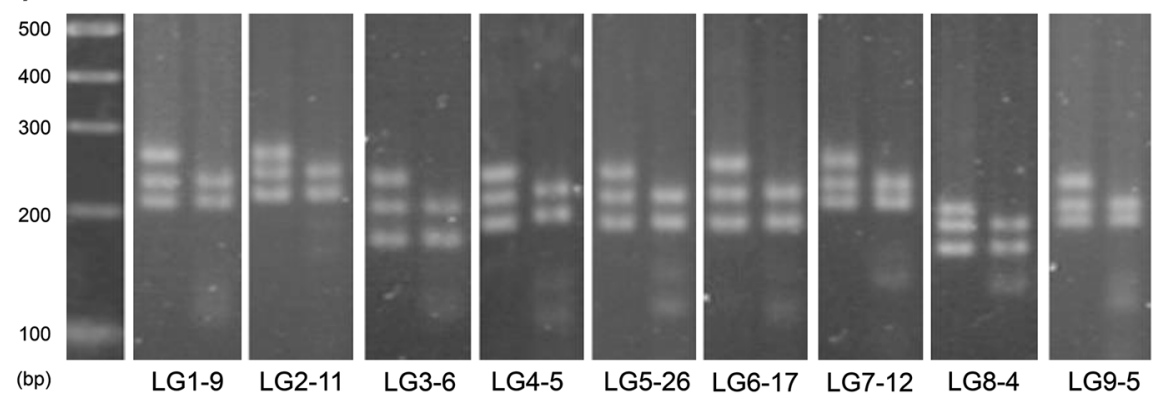

Fig. 2 Analysis of PCR products of Indel markers by microchip electrophoresis (a) and agarose electrophoresis (b). Precise measurement of the amplified PCR fragments was performed using a microchip electrophoresis system, and the separation was confirmed by agarose gel electrophoresis using a $4 \%$ gel visualized by staining with ethidium bromide which is a simple

and inexpensive DNA detection system that does not need advanced equipment. In the analysis, the left lane of each Indel maker was not treated with $\mathrm{T} 7$ endonuclease, whereas the right lane was treated with T7 endonuclease, a cleavage enzyme specific for heteroduplex DNA 
homozygous genotypes using the simple and inexpensive method "agarose gel electrophoresis."

In the crossing experiment, we hybridized two cultivars of Satsuma mandarin straines: "Imagawa" (female parent) and "EC11" (male parent). Using the resulting fruit, we performed embryo culture (Table 1). After crossing 1300 flowers, we obtained 112 seeded fruits $(31.1 \%)$ from 360 unripe fruits. As seeded fruits were not obtained without crossing $(0.0 \%, \mathrm{n}=100)$, seeds were not produced by self-pollination. The 112 seeded fruits produced 205 seeds $(1.83 \pm 1.28$ (S.D)/ fruit), from which we collected 1772 embryos $(8.64 \pm 4.72$ (S.D)/seed). There was a large statistical variability in both the number of seeds per fruit and the number of embryos per seed. A total of 1227 (69.2\%) of the embryos grew to seedlings large enough for DNA extraction.

Then, we used four types of different LGs Indel markers (LG1-9, LG2-11, LG3-6 and LG4-5) to find homozygous genotypes. Consequently, one or more Indel markers identified only one of the two homoduplex bands in 14 zygotic embryos $(1.14 \%)$. There was no significant difference ( $t$ test, $p<0.05$ ) between the number of embryos from seeds with zygotic embryos (6.71 \pm 3.71 (S.D.)/seed, $\max 13$, min 1 , $\mathrm{n}=14)$ and seeds without zygotic embryos $(8.79 \pm 4.77$ (S.D.)/seed, $\max 29, \min 1, \mathrm{n}=191)$. Zygotic embryos were obtained even from seeds with only one embryo. These zygotic embryos were explanted and cultured in vivo, and three zygotic embryos were acclimatized successfully. The acclimation success rate of zygotic-embryonic plants was $21.4 \%$ (3/14). For the genotyping of the three lines of plants derived from zygotic embryos, we performed agarose gel electrophoresis using nine Indel markers, one for each LG (Fig. 3). The zygotic embryo-derived lines $\mathrm{A}, \mathrm{B}$, and $\mathrm{C}$ had 4, 4, and 7 single bands, respectively, but the female parents had three bands. Thus, heterozygous genotypes were recombined into homozygous genotypes in multiple Indel regions by crossing between two parents.

Next, we investigated whether the 119 newly developed Indel markers could be used for genotyping using various citrus plants with diverse genotypes from several genera, known as true citrus plants [Satsuma mandarin (four cultivars bred by mutation), citrus cultivars other than Satsuma mandarin (eight cultivars bred by hybridization), one Fortunella species, and one Poncirus trifoliata]. The genotyping results are shown in Online Resource 3. We found the same heterozygous genotype in all four cultivars of Satsuma mandarin bred by mutation, showing clearly the Satsuma mandarin possesses the highly conserved heterozygous region detected by the Indel markers. In eight cultivars of the genus Citrus other than the Satsuma mandarin, which were bred by hybridization, more than $90 \%$ of the Indel markers were genotyped, and the different cultivars had different genotype combinations at each Indel marker. Furthermore, we detected more than $80 \%$ of the Indel markers in the genus Fortunella, and approximately $70 \%$ of the Indel markers in Poncirus trifoliata. Of the 119 markers, 61 were genotyped as LS, LL, or SS for all 14 cultivars and close relatives used in this study that contained Satsuma mandarin cultivars (markers in bold in Online Resource 3). Of the 61 markers, there were 8 markers that did not show polymorphism among the 10 cultivars and close relatives except for the Satsuma mandarin cultivars, and all of them were genotyped as LL (markers in bold italics in Online Resource 3).
Table 1 Processes from crossing to zygotic embryoderived seedlings in hybrids of Satsuma mandarin cultivars

\begin{tabular}{ll}
\hline Number of flowers pollinated & 1300 \\
Number of fruits set & 360 \\
Number of fruits containing seeds & 112 \\
Average seeds \pm S.D./fruit & $1.83 \pm 1.28$ \\
Number of seeds containing embryos & 205 \\
Average embryos \pm S.D./seed & $8.64 \pm 4.72$ \\
Number of embryo culture plants in vitro & 1772 \\
Hybrid assay by Indel marker & 1227 \\
Number of zygotic embryos & 14 \\
Number of nucellar embryos & 1213 \\
Number of acclimatized seedlings of zygotic embryos in vivo & 3 \\
\hline
\end{tabular}




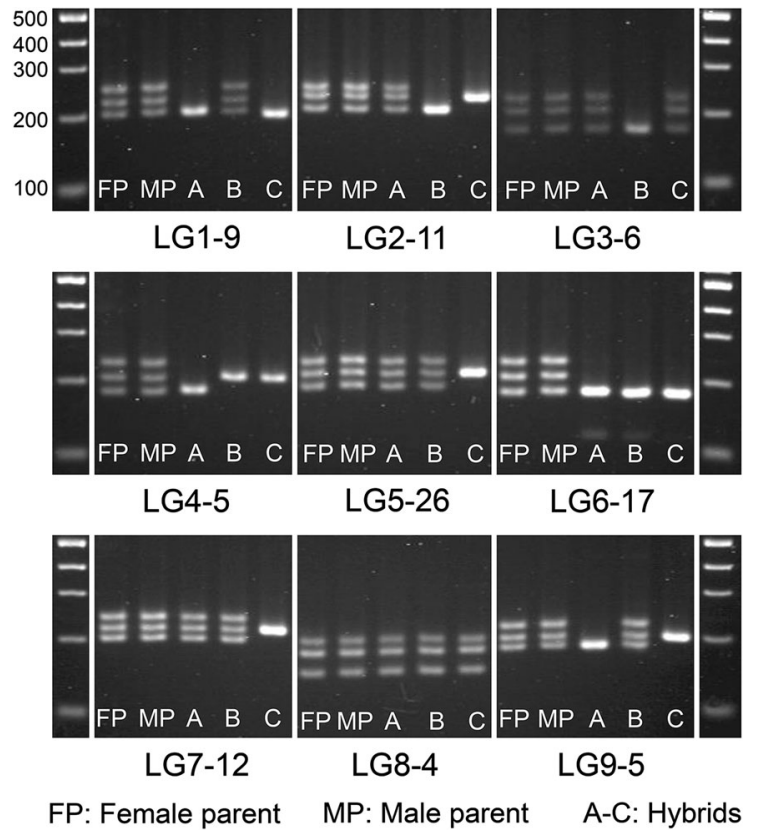

Fig. 3 Patterns of Indel markers on different chromosomes of acclimated hybrid seedlings. Lane FP: female parent; lane MP: male parent; lanes A-C: hybrid seedlings. Electrophoresis was performed on a $4 \%$ agarose gel. The first number of each Indel marker indicates the number of linkage groups (LGs) that were the same as the number of chromosomes

These findings indicate that the Indel markers that we developed are codominant DNA markers capable of detecting genomic regions that are highly conserved not only in Satsuma mandarins but also in a wide range of the true citrus plants.

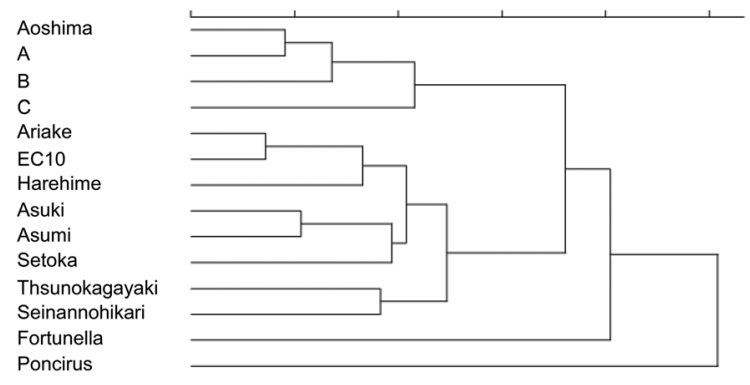

Fig. 4 Hierarchical clustering dendrograms based on genotype by Indel merkers. For cluster analysis, genotype of 119 Indel marker profiles were transformed into the matrix data where the LL is scored as 3, LS as 2, SS as 1, and N.D. as 0. Because genotype $\mathrm{X}$ was defined as a generic term that includes various band patterns other than LS, LL, or SS, it was treated as missing values in the matrix data. Cluster analysis was performed on the basis of a complete link method and square Euclidean distance
Based on these results, a dendogram by cluster analysis is shown in Fig. 4. Three lines A, B, and C obtained from hybrids between Satsuma mandarin cultivars were classified as clusters closer to Satsuma mandarin than other citrus cultivars. In Fortunella and Poncirus, which were tested as non-citrus species, Fortunella was classified as a cluster closer to Citrus than Poncirus.

\section{Discussion}

There are points to be aware of in the hybrid assay using the Indel marker. After crossing, the heterozygous genotype common to both parents may become homozygous in their offspring. When the genotype is homozygous, only one of the two fragments of homoduplex DNA can be detected. However, even if the cross is successful, the probability of changing from a heterozygous to a homozygous genotype at each locus is $50 \%$. Detection probability can be increased by using multiple Indel markers. For example, using four independent Indel markers, each derived from a different chromosome, can increase detection probability by $93.75 \%$. For this reason, we used four independent Indel markers developed from different LGs for the hybrid assay.

As the mean number of embryos was 8.64 per seed in the hybrid assay experiment using embryo rescue culture plants, we expected that the probability of successfully obtaining a zygotic embryo was more than $10 \%$ if one of the embryos in each seed is zygotic (1/8.64). However, the actual success rate for obtaining zygotic embryo was approximately $1 \%$. Moreover, the rate of success of acclimation of explanted zygotic embryos was $21.4 \%$ (3/14). These findings indicate that, for effective cross-breeding between Satsuma mandarin cultivars, two improvements are important: (1) increase the probability of obtaining a zygotic embryo, and (2) increase the rate of success of acclimation of explanted zygotic embryos.

Regarding the first issue: No studies identifying hybrids of Satsuma mandarins using DNA markers have been reported. However, a crossing experiment using Satsuma mandarin as the female parent and nonSatsuma polyembryonic citrus cultivars as the male parent has been reported (Horiuhi et al. 1990). In that study, based solely on morphological characteristics, $18.1 \%$ of the seedlings were considered to be derived 
from zygotic embryos. Compared to this previous study, we have a lower success rate of obtaining zygotic embryos in the current study. This may be due to our cultivar of male parent, the Satsuma mandarin, different from those of cited study. The affinity of male parents and female parents has been reported (Moller 1996), and this may have influenced the success rate of this study. If so, the rate of successfully obtaining zygotic embryos might be increased by finding suitable cultivars of Satsuma mandarin as the male parent.

In this study, we used the conventional approach of using seeds from immature fruit approximately 100 days after the crossing for in vitro embryo rescue culture (Deng et al. 1996; Tusa et al. 1996). There are reports of either poor embryo development (Liu et al. 2006) or developmental arrest (Frost 1926; Rodrangboon et al. 2002) in the early stage of zygotic embryogenesis in plants that produce polyembryonic seeds. Either of these problems may have occurred in the zygotic embryo-derived lines of Satsuma mandarins. Moreover, the rate of successfully obtaining zygotic embryos has been reported to depend on the stage of embryo acquisition (Rangan et al. 1969; Horiuchi et al. 1976). The success rate may be increased by changing the stage of embryo rescue. In polyembryonic seeds, zygotic embryos compete either nutritionally or spatially with multiple nucellar embryos, making continued growth of zygotic embryos difficult (Frost and Soost 1968; Soost and Citrus 1996). Therefore, in vitro embryo rescue culture is an effective way of increasing the probability of obtaining a zygotic embryo (Ohta and Furusato 1957). However, conducting embryo rescue timing earlier than that in our study may increase the rate of zygotic embryo acquisition.

A noteworthy result of our study is that zygotic embryos were obtained even when only one embryo was present in the seed. Furthermore, there was no significant difference between the number of embryos in seeds with and without zygotic embryos. From these results, it was considered that, among the many embryos that form in the seed, the survival rate of individual embryos is comparable between zygotic and nucellar embryos. This suggests that hybrid plants can be also selected from mature seed-derived plants. The method of obtaining hybrid plants from embryo rescue cultures, as shown in this study, require advanced equipment and high costs, although the probability of overlooking a zygotic embryo formed in the seed is low. In contrast, the method of obtaining hybrids from seed-derived plants is simple and does not require any special equipment, although there is concern about the increasing culling of zygotic embryos as the seeds mature. It is worth investigating which method is more efficient and practical for obtaining hybrid plants in the future.

Regarding the second issue: the growth of healthy seedlings in vivo requires the growth of healthy cultured embryonic-derived plants in vitro. Various studies have examined the relationship between the growth of plants obtained through embryo culture and the culture conditions (Horiuchi et al. 1976; Rangaswamy 1961; Carimi et al. 1998; Pérez-Tornero and Porras 2008; Jajoo 2010). Future research will need to identify a suitable medium for embryo culture of the Satsuma mandarin.

As citrus and its close relatives can be crossed between genera (Iwamasa et al. 1988), we used several of these plants to confirm whether our 119 newly developed Indel markers can be used for genotyping, and of the 119 Indel markers, 61 were genotypable to LS, LL, or SS in all citrus plants used in this study. It is suggested that these 61 Indel markers can be used to genotype various citrus species. When these Indel markers are used for the hybrid assay, a recombination between female parent and offspring can be used as an indicator of hybridization. That is, in the case of heterozygosity for either the female parent or the male parent (or both), the probability of the genotype of the hybridized embryo changing from heterozygous to homozygous or vice versa is $50 \%$. In this case, the probability of detection increases by increasing the number of Indel markers. Moreover, when the female parent and the male parent have different homozygous genotypes, the genotype of all hybridized embryos will be recombined into a heterozygous type only. In this case, one Indel marker detects the hybrid plant with a $100 \%$ detection rate, demonstrating that Indel markers developed from Satsuma mandarin genome information can be expected to serve as indicators of hybridization in a range of citrus plants beyond Satsuma mandarin cultivars.

The Indel markers developed in this study can be used to detect the genotype of each locus. The differences in the genotype combination at each locus have been applied to identify the cultivar; this is essential for protecting the breeder's rights. For 
example, the CAPS markers were used for this purpose (Ninomiya et al. 2015; Kunihisa 2011; Kunihisa et al. 2003). In cultivars bred by hybridization that were used in this study, the genotype combination for each Indel marker differs depending on the cultivar. Therefore, the newly developed Indel markers are not limited to detecting of hybridization and can be expected to have a range of applications, including identifying cultivars which are bred by hybridization.

The dendrogram obtained from cluster analysis showed that Fortunella is genetically more similar to citrus than to Poncirus. Both nuclear and chloroplast DNA analysis revealed that Fortunella is nested within the citrus clade (Garcia-Lor et al. 2013; CarbonellCaballero et al. 2015; Nagano et al. 2018; Wu et al. 2018). Conversely, the chloroplast sequence of Poncirus is nested within the citrus clade (Penjor et al. 2013; Carbonell-Caballero et al. 2015); however, nuclear DNA analysis revealed that Poncirus is an outgroup of the remaining true citrus plants, likely because a non-citrus plant may be paternal parent of Poncirus (Nagano et al. 2018; Wu et al. 2018). Our DNA analysis matched the findings of these previous studies.

Nearly all of the Indel markers developed here are available widely for analysis of various citrus species. In this study, the Indel markers were developed using data from Satsuma mandarin, but they can be easily developed in other citrus species. Whole genome resequencing of citrus species costs less than $\$ 400$. The availability of public whole genome data as reference genomes and the low cost of resequencing make it possible to develop new DNA markers inexpensively. Moreover, if the reference genome sequence of the target species is available, this inexpensive and convenient approach can be used for species other than Citrus.

Acknowledgements The authors would like to thank Naomi Matsuda for technical assistance with the experiments. Part of this work was supported by a Grant-in-Aid for Scientific Research (18K05623 to Yukio Nagano) from the Japan Society for the Promotion of Science.

Open Access This article is licensed under a Creative Commons Attribution 4.0 International License, which permits use, sharing, adaptation, distribution and reproduction in any medium or format, as long as you give appropriate credit to the original author(s) and the source, provide a link to the Creative Commons licence, and indicate if changes were made. The images or other third party material in this article are included in the article's Creative Commons licence, unless indicated otherwise in a credit line to the material. If material is not included in the article's Creative Commons licence and your intended use is not permitted by statutory regulation or exceeds the permitted use, you will need to obtain permission directly from the copyright holder. To view a copy of this licence, visit http://creativecommons.org/licenses/by/4.0/.

Author contributions Takahiro Noda, Kaoru Daioua and Yukio Nagano conceived, and designed the experiments. Yukio Nagano and Takahiro Noda analyzed NGS data for mining of Indel regions. Takashi Mihara prepared citrus genetic resources and conducted a citrus crossing experiment. Takahiro Noda and Kaoru Daioua performed most of the experiments. The manuscript was written by Takahiro Noda and edited by Yukio Nagano, and then reviewed by all authors.

\section{References}

Albach RF, Redman GH (1969) Composition and inheritance of flavanones in Citrus fruit. Phytochemistry 8:127-143. https://doi.org/10.1016/S0031-9422(00)85805-7

Anderson CM, Castle WS, Moore GA (1991) Isozymic identification of zygotic seedlings in Swingle citrumelo Citrus paradise $\times$ Poncirus trifoliata nursery and field populations. J Am Soc Hort Sci 16:322-326. https://doi.org/10. 21273/JASHS.116.2.322

Ashari S, Aspinall D, Sedgley M (1988) Discrimination of zygotic and nucellar seedlings of five polyembryonic citrus rootstocks by isozyme analysis and seedling morphology. J Hort Sci 63:695-703. https://doi.org/10.1080/14620316. 1988.11515912

Bastianel M, Schwarz SF, Coleta Filho HD, Lin LL, Machado MA, Koller OC (1998) Identification of zygotic and nucellar tangerine seedlings (Citrus spp.) using RAPD. Genet Mol Biol 21:123-127. https://doi.org/10.1590/ S1415-47571998000100020

Bolger AM, Lohse M, Usadel B (2014) Trimmomatic: a flexible trimmer for Illumina sequence data. Bioinformatics 30:2114-2120. https://doi.org/10.1093/bioinformatics/ btu 170

Bowman KD, Gmitter FG, Hu X (1995) Relationships of seed size and shape with polyembryony and the zygotic or nucellar origin of Citrus species seedlings. HortScience 30:1279-1282. https://doi.org/10.21273/HORTSCI.30.6. 1279

Cameron JW, Soost RK (1979) Sexual and nucellar embryonyin F1 hybrids and advanced crosses of Citrus with Pon-cirus. J Am Soc Hort Sci 104:408-410

Carbonell-Caballero J, Alonso R, Ibañez V, Terol J, Talon M, Dopazo J (2015) A phylogenetic analysis of 34 chloroplast genomes elucidates the relationships between wild and domestic species within the genus Citrus. Mol Biol Evol 32:2015-2035. https://doi.org/10.1093/molbev/msv082 
Carimi F, De Pasquale F, Puglia AM (1998) In vitro rescue of zygotic embryos of sour orange, Citrus aurantium L., and their detection based on RFLP analysis. Plant Breed 117:261-266. https://doi.org/10.1111/j.1439-0523.1998. tb01936.x

Carlos de Oliveira A, Novac Garcia A, Cristofani M, Machado MA (2002) Identification of citrus hybrids through the combination of leaf apex morphology and SSR markers. Euphytica 128:397-403. https://doi.org/10.1023/A: 1021223309212

Danecek P, Auton A, Abecasis G, Albers CA, Banks E, DePristo MA, Handsaker RE, Lunter G, Marth GT, Sherry ST, McVean G, Durbin R, 1000 Genomes Project Analysis Group (2011) The variant call format and VCFtools. Bioinformatics 27:2156-2158. https://doi.org/10.1093/ bioinformatics/btr330

Defay D (1977) An efficient algorithm for a complete link method. Comput J 20:364-366

Deng XX, Yi HL, Li F, Guo WW (1996) Triploid plantsregenerated form crossing diploid pummelo and tangerinewith allotetrapolid somatic hybrid of Citrus. Proc Intl Soc Citricult 1:189-192

Esen A, Soost RK (1974) Inherence of browning of young-shoot extracts of Citrus. J Hered 65:97-100. https://doi.org/10. 1093/oxfordjournals.jhered.a108482

Frost HB (1925) Tetraploidy in Citrus. Proc Natl Acad Sci USA 11:535-537. https://doi.org/10.1073/pnas.11.9.535

Frost HB (1926) Polyembryony, heterozygosis and chimeras in citrus. Hilgardia 1:365-402. https://doi.org/10.3733/hilg. v01n16p365

Frost HB, Soost RK (1968) Seed reproduction: development of gametes and embryos. In: Reuther W, Batchelor LD, Webber HJ (eds) The citrus industry, vol 2. University of California Press, Berkeley, pp 290-324

Furr JR, Reece PC (1946) Identification of hybrid and nucellar citrus seedlings by a modification of the rootstock color test. J Am Soc Hort Sci 48:141-146

Garcia-Lor A, Curk F, Snoussi-Trifa H, Morillon R, Ancillo G, Luro F, Navarro L, Ollitrault P (2013) A nuclear phylogenetic analysis: SNPs, indels and SSRs deliver new insights into the relationships in the 'true citrus fruit trees' group (Citrinae, Rutaceae) and the origin of cultivated species. Ann Bot 111:1-19. https://doi.org/10.1093/aob/ $\operatorname{mcs} 227$

Horiuchi S, Yuda E, Nakagawa S (1976) In vitro culture of young embryo in polyembryonic citrus (I). J Jpn Soc 45:253-260 (in Japanese with English abstract)

Horiuhi S, Yuda E, Nakagawa S, Morimoto J, Gato Y (1990) Shapes of seed including well-developed zygotic embryo in polyembryonic Citrus species/cultivars. J Jpn Soc Hort Sci 59:225-235. https://doi.org/10.2503/jjshs.59.225 (in Japanese with English abstract)

Iglesias L, Lima H, Simon JP (1974) Isozyme identification of zygotic and nucellar seedlings in Citrus. J Hered 65:81-84. https://doi.org/10.1093/oxfordjournals.jhered.a108478

Iwamasa M, Nito N, Ling JT (1988) Intra- and intergeneric hybridization in the orange subfamily, Aurantioideae. In: Goren R, Mendel K (eds) Proceedings of international citrus congress, vol 1. Margrat Publishers, Weikersheim, pp 123-130
Jajoo A (2010) In vitro propagation of Citrus limonia Osbeck through nucellar embryo culture. Curr Res J Bio Sci 2:68

Jannati M, Fotouhi R, Pourjanabad A, Salehi Z (2009) Genetic diversity analysis of Iranian citrus varieties using micro satellite (SSR) based markers. J Hortic For 1:120-125

Kaneyoshi J, Kanou T, Kuwata Y, Hirao A, Nakatani S, Kobayashi S (1997) Breeding of triploid citrus cultivars I. Production of triploids from Satsuma mandarin (Citrus unshiu Marc.) X tetraploid ponkan mandarin (Citrus reticulata Blanco) crosses. Jpn Soc Hort Sci 66:9-14. https://doi.org/10.2503/jjshs.66.9 (in Japanese with English abstract)

Kunihisa M (2011) Studies using DNA markers in Fragaria $\times$ ananassa: genetic analysis, genome structure, and cultivar identification. J Jpn Soc Hortic Sci 80:231-243. https://doi.org/10.2503/jjshs1.80.231

Kunihisa M, Fukino N, Matsumoto S (2003) Development of cleavage amplified polymorphic sequence (CAPS) markers for identification of strawberry cultivars. Euphytica 134:209-215. https://doi.org/10.1023/B:EUPH. 0000003884.19248 .33

Li H, Durbin R (2009) Fast and accurate short read alignment with Burrows-Wheeler transform. Bioinformatics 25:1754-1760. https://doi.org/10.1093/bioinformatics/ btp324

Li H, Ruan J, Durbin R (2008) Mapping short DNA sequencing reads and calling variants using mapping quality scores. Genome Res 18:1851-1858. https://doi.org/10.1101/gr. 078212.108

Li H, Handsaker B, Wysoker A, Fennell T, Ruan J, Homer N, Marth G, Abecasis G, Durbin R, 1000 Genome Project Data Processing Subgroup (2009) The sequence alignment/ map format and SAMtools. Bioinformatics 25:2078-2079. https://doi.org/10.1093/bioinformatics/btp352

Liu H, Yan G, Sedgley R (2006) Interspecific hybridization in the genus Leucadendron through embryo rescue. S Afr J Bot 72:416-420. https://doi.org/10.1016/j.sajb.2005.11. 003

Liu TJ, Li YP, Zhou JJ, Hu CG, Zhang JZ (2018) Genome-wide genetic variation and comparison of fruit-associated traits between kumquat (Citrus japonica) and Clementine mandarin (Citrus clementina). Plant Mol Biol 96:493-507. https://doi.org/10.1007/s11103-018-0712-2

McKenna A, Hanna M, Banks E, Sivachenko A, Cibulskis K, Kernytsky A, Garimella K, Altshuler D, Gabriel S, Daly M, DePristo MA (2010) The genome analysis toolkit: a mapreduce framework for analyzing next-generation DNA sequencing data. Genome Res 20:1297-1303. https://doi. org/10.1101/gr.107524.110

Moller AP (1996) Developmental stability of flowers, embryo abortion, and developmental selection in plants. Proc R Soc Lond B263:53-56. https://doi.org/10.1098/rspb.1996.0009

Mondal B, Saha R (2014) Identification of zygotic and nucellar seedlings of Citrus reticulata and Citrus aurantifolia using RAPD. Int J Adv Biotechnol Res 5:25-30

Moore GA, Castle WS (1988) Morphological and isozymic analysis of open-pollinated Citrus rootstock populations. J Hered 79:59-63. https://doi.org/10.1093/oxfordjournals. jhered.a110448

Murashige T, Skoog F (1962) A revised medium for rapid growth and bioas-says with tobacco tissue cultures. Physiol 
Plant 15:473-497. https://doi.org/10.1111/j.1399-3054. 1962.tb08052.x

Nagano Y, Mimura T, Kotoda N, Matsumoto R, Nagano AJ, Honjo MN, Kudoh H, Yamamoto M (2018) Phylogenetic relationships of Aurantioideae (Rutaceae) based on RADSeq. Tree Genet Genomes 14:6. https://doi.org/10.1007/ s11295-017-1223-z

Nakamura M (1929) Cytological studies in the genus citrus. I. On the Wase satsuma originated through bud variation. Stud Citrol 3:1-14

Ninomiya T, Shimada T, Endo T, Nonaka K, Omura M, Fujii H (2015) Development of citrus cultivar identification by CAPS markers and parentage analysis. Hort Res (Japan) 14:127-133. https://doi.org/10.2503/hrj.14.127 (in Japanese with English abstract)

Nishiura M (1964) Citrus breeding and bud selection in Japan. Florida State Hortic Soc 77:79-83

Nishiura M (1968) Mutation in citrus. Jpn Agric Res Q 3:10-14

Ohta Y, Furusato K (1957) Embryo culture in citrus. SeikenZilho. Rpt Kihara Inst Bio Res 23:49-54

Omura M, Shimada T (2016) Citrus breeding, genetics and genomics in Japan. Breed Sci 66:3-17. https://doi.org/10. $1270 /$ jsbbs.66.3

Penjor T, Yamamoto M, Uehara M, Ide M, Matsumoto N, Matsumoto R, Nagano Y (2013) Phylogenetic relationships of citrus and its relatives based on matK gene sequences. PLoS ONE 8:e62574. https://doi.org/10.1371/journal. pone. 0062574

Pérez-Tornero O, Porras I (2008) Assessment of polyembryony in lemon: rescue and in vitro culture of immature embryos. Plant Cell Tissue Organ Cult 93:173-180. https://doi.org/ 10.1007/s11240-008-9358-0

Pieringer AP, Edwards GJ (1967) Identification of nucellar and zygotic citrus seedlings by infrared spectroscopy. J Am Soc Hort Sci 86:226-234

Rangan TS, Murashige T, Bitters WP (1969) In vitro studies of zygotic and nucellar embryogenesis in citrus. In: Proceedings of 1 st international citrus symposium, vol 1, pp 225-229

Rangaswamy NS (1961) Experimental studies on female reproductive structures of Citrus microcarpa. Bunga Phytomorphol 11:109-127

Rao MN, Soneji JR, Chen C, Huang S, Gmitter FG (2008) Characterization of zygotic and nucellar seedlings from sour orange-like citrus rootstock candidates using RAPD and EST-SSR markers. Tree Genet Genomes 4:113-124

Rodrangboon $\mathrm{P}$, Pongtongkam P, Suputtitada S, Adachi T (2002) Abnormal embryo development and efficient embryo rescue in interspecific hybrids, Oryza sativa $\times O$. minuta and $O$. sativa $\times O$. officinalis. Breed Sci 52:123-129. https://doi.org/10.1270/jsbbs.52.123

Ruiz C, Paz Breto MP, Asíns MJ (2002) A quick methodology to identify sexual seedlings in citrus breeding programs using SSR markers. Euphytica 112:89-94. https://doi.org/10. 1023/A:1003992719598

Shareefa M, Singh AK, Manish S, Dubey AK (2009) Differentiation of nucellar and zygotic seedlings in citrus using ISSR markers. Indian J Agr Sci 79:884-889

Shimada T, Fujii H, Endo T, Ueda T, Sugiyama A, Nakano M, Kita M, Yoshioka T, Shimizu T, Nesumi H, Ikoma Y, Moriguchi T, Omura M (2014) Construction of a citrus framework genetic map anchored by 708 gene-based markers. Tree Genet Genomes 10:1001-1013. https://doi. org/10.1007/s11295-014-0738-9

Shimizu T, Tanizawa Y, Mochizuki T, Nagasaki H, Yoshioka T, Toyoda A, Fujiyama A, Kaminuma E, Nakamura Y (2017) Draft sequencing of the heterozygous diploid genome of Satsuma (Citrus unshiu Marc.) using a hybrid assembly approach. Front Genet 8:180. https://doi.org/10.3389/ fgene.2017.00180

Soost RK, Citrus RM (1996) In: JulesJ MooreJN (ed) Fruit breeding: tree and tropical fruits, vol 1. Wiley, New York, pp 257-323

Stanley WL, Jurd L (1971) Citrus coumarins. J Agric Food Chem 19:1106-1110. https://doi.org/10.1021/jf60178a007

Tatum JH, Berry RE, Hearn CJ (1974) Characterization of Citrus cultivars and separation of nucellar and zygotic seedlings by thin layer chromatography. Proc Fla State Hort Soc 87:75-81

Thorvaldsdóttir H, Robinson JT, Mesirov JP (2013) Integrative Genomics Viewer (IGV): high-performance genomics data visualization and exploration. Brief Bioinform 14:178-192. https://doi.org/10.1093/bib/bbs017

Tusa N, Fatta DB, Nardi L, Lucretti S (1996) Obtaining triploid plants by crossing Citrus Lemoncv 'Femminello' $2 \mathrm{~N} \times 4$ $\mathrm{N}$ allotetraploid somatic hybrids. Proc Int Soc Citricult $1: 133-136$

Vilarinhos AD, Pereira VCH, Soares-FilhoWdos S, Nickel O, Oliveira RP (2000) Marcadores RAPD na avaliação da diversidade genética e na identificação de híbridos interespecíficos de Citros. Rev Bras Frut 22:14-19

Wang X, Xu Y, Zhang S, Cao L, Huang Y, Cheng J, Wu G, Tian S, Chen C, Liu Y, Yu H, Yang X, Lan H, Wang N, Wang L, Xu J, Jiang X, Xie Z, Tan M, Larkin RM, Chen LL, Ma BG, Ruan Y, Deng X, Xu Q (2017) Genomic analyses of primitive, wild and cultivated citrus provide insights into asexual reproduction. Nat Genet 49:765-772. https://doi. org/10.1038/ng.3839

Wang L, He F, Huang Y, He J, Yang S, Zeng J, Deng C, Jiang X, Fang Y, Wen S, Xu R, Yu H, Yang X, Zhong G, Chen C, Yan X, Zhou C, Zhang H, Xie Z, Larkin RM, Deng X, Xu Q (2018) Genome of wild mandarin and domestication history of mandarin. Mol Plant 11:1024-1037. https://doi.org/ 10.1016/j.molp.2018.06.001

Weinbaum SA, Cohen E, Spiegel-Roy P (1982) Rapid screening of 'Satsuma' mandarin progeny to distinguish nucellar and zygotic seedlings. Hort Sci 17:239-240

Woo JK, Park YC, Lee JW, Yun SH, Kim M, Park S, Lee Y, Song KJ, Kim HB (2019) Evaluation of polyembryony for genetic resources and efficacy of simple sequence repeat markers for the identification of nucellar and zygotic embryo-derived individuals in citrus. Appl Biol Chem 62:30. https://doi.org/10.1186/s13765-019-0437-1

Wu GA, Terol J, Ibanez V, López-García A, Pérez-Román E, Borredá C, Domingo C, Tadeo FR, Carbonell-Caballero J, Alonso R, Curk F, Du D, Ollitrault P, Roose ML, Dopazo J, Gmitter FG, Rokhsar DS, Talon M (2018) Genomics of the origin and evolution of Citrus. Nature 554:311-316. https://doi.org/10.1038/nature25447

Yamamoto M, Matsumoto R, Yamada Y (1995) Relationship between sterility and seedlessness in citrus. J Jpn Soc Hort Sci 64:23-29. https://doi.org/10.2503/jjshs.64.23 
Yang HJ, Nakagawa S (1969) Cyto-histological studies on the male sterility of Satsuma orange (Citrus unshiu Marc.). Engei Gakkai zasshi 38:239-245. https://doi.org/10.2503/ jjshs.38.239

Yang H, Nakagawa S (1970) Studies on the male sterility of Satsuma orange (Citrus unshiu MARC.). Engei Gakkai zasshi 39:6-20. https://doi.org/10.2503/jjshs.39.6

Yildiz E, Kaplankiran M, Demİrkeser TH, Uzun A, Toplu C (2013) Identification of zygotic and nucelar individuals produced from several Citrus crosses using SSRs markers. Not Bot Hor Agrobot 41:478-484. https://doi.org/10. 15835/nbha4129037

Publisher's Note Springer Nature remains neutral with regard to jurisdictional claims in published maps and institutional affiliations. 